\title{
Editorial
}

\section{¿La universidad para profesionalizar o para el desarrollo cultural?}

\author{
Vladimir Ramírez Tarazona
}

$\mathrm{L}$

a educación universitaria según la Constitución Política colombiana de 1991 es un derecho de las personas y un servicio público con una función social, en principio deberá formar para el mejoramiento cultural, científico y tecnológico en un marco de protección del medio ambiente. Para ello fija unos compromisos de formación moral, física e intelectual, asegurando para los ciudadanos el acceso y permanencia dentro del sistema. Entre las principales novedades y aportes se pueden citar el desarrollo de la autonomía institucional y se definen cuatro tipos de instituciones, técnicas superiores, tecnológicas, universitarias y universidades, se creó el Consejo Nacional de Educación Superior (CESU) como órgano de inspección y vigilancia y el Sistema Nacional de Acreditación para garantizar los altos requisitos de calidad, definiendo como campos de acción el de la técnica, la ciencia, la tecnología, las humanidades, el arte y la filosofía.

La coyuntura sobre la cual emerge el Sistema Nacional de Educación Terciaria (SNET) más allá de su planeamiento central que gira en torno a la unificación de la educación técnica y tecnológica de formación para el trabajo con la educación superior, desató el debate sobre la pertinencia de una universidad profesionalizante, que no se sabe con exactitud qué es y para qué sirve. suponemos que sea para el mejoramiento cultural, científico y tecnológico como para una formación física, intelectual y en valores. Claramente nuestro sistema educativo no ha logrado cumplir con estos compromisos y se ha enfrascado en reformas fallidas del sector, cada vez más distantes de la necesidad ciudadana, incapaz para crear nuevos escenarios, con presupuestos más reducidos y con una cobertura cada vez menor.

En el debate sobre la actualidad educativa un aspecto cobra cada vez mayor relevancia, ¿si es suficiente para una sociedad una universidad que prepare a sus actores para las labores productivas o si por el contrario debe estar para la búsqueda de un desarrollo cultural, aunque esté cada vez más ávida de cerrar las brechas desarrollistas? Lastimosamente este debate se da solo entre especialistas e intelectuales a quienes les interesa el futuro de la educación, ya que lo que hoy vemos en la universidad es una sobrevaloración del interés del estudiante, quien realmente se encuentra más seducido por el hedonismo contemporáneo y su vida social y no entiende los diversos intereses universitarios, en la que paulatinamente se incorporan prácticas didácticas para adaptarse al impacto generacional.

Paradójicamente la educación continúa cimentándose en la valoración del conocimiento fijo y la técnica, concediéndole demasiada importancia a la autoridad, especialmente del profesor que es la fuente del conocimiento, y rara vez es cuestionada, pero que también se observa en el conocimiento mismo, fuente de la verdad. Se necesita por supuesto un cierto orden y autoridad en el aula, y un conocimiento que debe ser compartido y comunicado por el profesor, pero cuando la educación solamente se fundamenta en estas circunstancias, el conformismo va cimentándose no solo en los estudiantes y profesores, sino que se irradia a la sociedad, la gran ausente en este proceso educativo, razón por la cual esta situación se reproduce, por ejemplo, en el trabajo, donde la autoridad y la disciplina se van tornando rutinarias, motivando temores, presiones arbitrarias y esperanzas de recompensas, considerándose estas como necesarias y valiosas, y el desarrollo cultural se torna irrelevante.

Tenemos una universidad que de alguna manera compartimos con otros sistemas educativos y sociales, en lo que se puede denominar un proyecto global universitario, que presenta algunas características similares que han tenido eco en el sistema educativo latinoamericano, específicamente en la acogida relacionada con el diseño 
de currículos basados en competencias, un tipo tradicional de transmisión de contenidos, el uso cada vez más frecuente de los medios digitales, una investigación educativa centrada en el tema operativo y la enseñanza aplicada a un contexto socioproductivo.

La inclinación señalada surge como parte fundamental en el desempeño académico y laboral, que se despliega dentro del proceso de calidad direccionado desde la formación por competencias en la educación superior, de esta manera la habilidad del docente genera un proceso fundamental que no coadyuva en la construcción de una universidad contemporánea inspirada en valores humanísticos y de bienestar real en la sociedad.

Ahora bien, en los años noventa, a partir de la aplicación de la Ley 30 nacida de la Constitución Política, la universidad se centra en la búsqueda de la calidad y de la internacionalización, se creó un sistema educativo de educación superior que dejara atrás los métodos fundamentados en la memorización y la trasmisión de datos a una educación universitaria enfocada a la resolución de problemas, dentro de un ámbito de investigación fundamentalmente vinculada al aparato productivo. La universidad fue puesta entonces en la mira del mercado global, lo que determinó que dentro de ella se tejieran un sinnúmero de estrategias de las cuales es difícil separarse, y cualquier análisis pasa por entender primero las fuerzas que influyen en su gobierno.

En este orden de ideas, la enseñanza que se produce en su interior no es ajena a las dinámicas del mercado, por el contrario, la estremece, debido a las presiones institucionales por establecer un liderazgo instrumental que transita por el desarrollo del sistema de la educación superior fundamentado en la difusión de los parámetros oficiales de Ciencia, Tecnología e Innovación. Estos fundamentan las políticas públicas inducidas por un desarrollo económico que determina la creación de un mercado de servicios universitarios. Al respecto, estamos en acuerdo con Boaventura Da Sousa para quien:

La afirmación de la autonomía de las universidades se dio al mismo tiempo con la privatización de la educación superior y el incremento de la crisis financiera de las universidades públicas" que perfila la apertura generalizada de su explotación comercial. (Da Sousa, 2007: 25)

Esta transformación define un tipo de educación diferente, y por inferencia un tipo de enseñanza diferente, donde el estudiante se convierte en consumidor y el conocimiento universitario es predominantemente profesionalizante que deviene de las necesidades del modo de producción, y se mantiene relativamente descontextualizado de las necesidades del tejido social y de la autorrealización. De esta manera se crea una profunda fractura de identidad social y cultural de esta, traducida en desorientación táctica, reflejada sobre todo en una cierta actitud paradójica de resistencia al cambio en nombre de la autonomía universitaria y de la libertad académica. La inestabilidad causada por el impacto de estas presiones contrapuestas crea un impase donde se torna evidente la exigencia de mayores cambios, evidenciando que la pretendida calidad de los lineamientos constitucionales son una quimera.

En conclusión, el sistema global, que podríamos calificar de neoliberal en el mundo contemporáneo, plantea un tipo de educación que sirve al aparato productivo, pero no a la creación de salidas a su crisis, no se encamina a generar personas comprometidas con su sociedad. En vía contraria el sistema educativo presenta una planificación de las tareas que también da origen al planteamiento curricular, como un lineamiento institucional que determina de una manera anticipada lo que se podría esperar de los diferentes cursos educativos. Esta manera de desarrollar el proceso educativo ha tenido cabida en un gran número de instituciones de carácter superior, presuponiendo que la mayoría de estudiantes deben lograr los objetivos deseados o propuestos, y es lógico suponer que los métodos de enseñanza también se comparten, dejando muy poco espacio de maniobra pedagógica a los profesores.

Lo que realmente encontramos es una inercia educativa, en la cual, un elemento es lo programado y otro muy diferente es lo que se va realizando en el espacio académico, en donde se encuentran ritmos diversos de aprendizaje y los contenidos esperados suelen diferir de un estudiante a otro, o de un curso a otro; en términos concretos, lo que se tiene programado no es lo que realmente sucede, además, la heterogeneidad de los estudiantes no se puede calcular de la misma manera que se calculan los objetivos, dando como consecuencia que tanto docentes como estudiantes imposibilitan la comprensión de la realidad. 
Como consecuencia, los procesos evaluativos no arrojan los resultados previstos para los contenidos adquiridos de los estudiantes, y por lo tanto, no ofrecen información confiable al respecto de los procesos de calidad promocionados, ni de su contexto, realidad que debería ser el centro del debate. Tenemos por el contrario propuestas, que emergen de sectores ajenos que promueven mezclas conceptuales sobre la clasificación de las instituciones educativas, sin ningún referente, que nada aportan a la sostenibilidad cultural, científica, ni tecnológica, por lo tanto, tampoco al aparato productivo que pretende impactar.

\section{Referencias bibliográficas}

Da sousa, B.(2007). La universidad en el siglo xxi para una reforma democrática y emancipadora de la universidad. La Paz: Plural Editores. 